\title{
Modeling for Green Supply Chain Evaluation
}

\author{
Elham Falatoonitoosi, ${ }^{1}$ Zulkiflle Leman, ${ }^{1}$ and Shahryar Sorooshian ${ }^{2}$ \\ ${ }^{1}$ Department of Mechanical and Manufacturing Engineering, Universiti Putra Malaysia (UPM), 43300 Serdang, Selangor, Malaysia \\ ${ }^{2}$ Faculty of Technology, University Malaysia Pahang (UMP), Malaysia
}

Correspondence should be addressed to Shahryar Sorooshian; sorooshian@gmail.com

Received 13 January 2013; Revised 17 March 2013; Accepted 18 March 2013

Academic Editor: Shengyong Chen

Copyright (C) 2013 Elham Falatoonitoosi et al. This is an open access article distributed under the Creative Commons Attribution License, which permits unrestricted use, distribution, and reproduction in any medium, provided the original work is properly cited.

\begin{abstract}
Green supply chain management (GSCM) has become a practical approach to develop environmental performance. Under strict regulations and stakeholder pressures, enterprises need to enhance and improve GSCM practices, which are influenced by both traditional and green factors. This study developed a causal evaluation model to guide selection of qualified suppliers by prioritizing various criteria and mapping causal relationships to find effective criteria to improve green supply chain. The aim of the case study was to model and examine the influential and important main GSCM practices, namely, green logistics, organizational performance, green organizational activities, environmental protection, and green supplier evaluation. In the case study, decision-making trial and evaluation laboratory technique is applied to test the developed model. The result of the case study shows only "green supplier evaluation" and "green organizational activities" criteria of the model are in the cause group and the other criteria are in the effect group.
\end{abstract}

\section{Introduction}

Environmental protection is becoming more and more important for enterprises because of stronger public awareness, competitors and communities, and government regulations. For this purpose, some programs become more popular for environmentally aware performing including total quality environmental management, ISO 14000 standards, and green supply chain management. Reducing the environmental pollution from upstream to downstream during procuring raw materials, producing, distribution, selling products, and products depreciation is the most important goal of green supply chain management (GSCM).

Indeed, there is no research that determines main factors in a whole green supply chain system or specify their power of influence on each other to find their role in a system. This study fills this gap by presenting a model that consists of five main practices to improve GSCM by selecting green supplier.

Supplier selection is a fundamental issue of supply chain area which heavily contributes to the overall supply chain performance [1]. Suppliers' development is a critical function within supply chain management. Green supplier improvement is also essential for effective green supply chain management.

Supply Chain managers could minimize the products' environmental impact based on some related environmental criteria. It harmonizes the economic, customer value, manufacturability, and other factors that may also be evaluated. Additionally, buyer-supplier relations play an increasingly important role in addressing environmental issues. The third concern is that firms should change their environmental performance methods in order to incorporate environmental concerns of external sources. Therefore, a system analysis is needed to integrate environmental management with the greening of the supply chain. Supply $c$ managers must consider the complete environmental impact of a product during its entire life cycle, including raw material, manufacturing/assembly processes, distribution, use, and disposal. The environmental effects include material, energy, air, water, and solid waste pollution [2].

The main and basic challenges in the green supply chain are modeling a strategy to manage the resources and meet the demands [3]. Select the green suppliers that will deliver the goods and services that are required to manufacture the 
product, deliver the product to the customers environmentally, and arrange for return of the product for servicing through customers, if there is any fault in the product. This study concentrates mainly on the supplier selection problem. Selecting suitable suppliers for purchasing the raw materials is an important part of the operation $[4,5]$.

The decision of selecting the right supplier is prone to errors. The right supplier is the one who will meet and complement the organization's needs from its corporate culture to long-term future requirements $[6,7]$. Today, buyers are willing to purchase products and services from suppliers that manage to provide them with high quality, low cost, and short lead time with environmental responsibility at the same time because of increasing environmental attentiveness. On the contrary, a number of criteria are quantitative such as "price of the product," "lead time for delivery," "transportation cost," and so forth [8]; whereas some, like "pollution control," "reducing the waste," "quality of service," and so forth, are qualitative [9]. No single methodology appears to be dominant in solving the supplier selection problem [10].

In the last century, the most important challenge for enterprises has been integrating of social, environment, and economic performance to obtain sustainable improvement [11]; in other words, if firms want to survive in the global market they cannot disregard environmental issues. In spite of traditional supplier selection that focused on price, quality, and delivery on time [12] or concentrated only on the requirements of single organizations and lose to consider the whole supply chain [13], green supplier selection processes have to focus on improving environmental factors in whole supply chain through organizational performance and activities, consumption, logistics, customer service, and financial performance concurrently $[14,15]$.

One of the most obvious gaps by considering to previous studies is the large number of mathematical and quantitative models that have been applied for selecting green suppliers such as AHP (Analytic Hierarchy Process) technique [16, 17], fuzzy comprehensive evaluation [10], comprehensive grade model [18]. grey widespread evaluation [9], and so forth. In fact, the nature of supplier selection is both quantitative and qualitative; therefore, the quantitative models could not be reliable enough. On the other hand, some of these quantitative methods have complicated calculation, while others cannot avoid subjective presumption [8]. As well, there is not any consideration to complex causal relationship between criteria of the system along dependences and feedbacks among criteria and alternatives simultaneously [13]. Therefore, the DEMATEL technique is applied in this study to examine both direct and indirect effects among green practices and visualize the causal relationships among them.

\section{Literature Review}

2.1. Supply Chain and Green Supply Chain Management. The concepts of supply chain management (SCM) and supply chain have been remarked as one major trend of the management. The Supply chain has been known to comprise of suppliers, manufacturers, retailers, transporters, warehouses, and customers; these are all directly or indirectly helped in customer request fulfillment [19]. Moreover, coordination benefits were revealed by the partners of supply chain [20], thus making SCM to become organizations critical strategy to formulate competitive benefits [21].

The supply chain includes not only suppliers and manufacturers, but also warehouses, retailer's transporters, and consumers themselves. A supply chain is a distribution and facility network that carries out the activities of material procurement and its reformation into finished and intermediary products as well as the finished products distribution to customers $[22,23]$. The monitoring of environmental management programs of GSCM is reactive, proactive practices including reverse logistics, recycling, and remanufacturing. However, [24] believed that it is an innovative chain supply management from green purchase, green packaging, green manufacturing, and reverse logistics.

For the companies transfer to the "green" of their supply chain, motivators should be different. Although some of the motivators are unclear, according to, some of the organizations do this due to the fact that it is the right thing for the environment. Although some are more radical for the change of the environment while others may not [25], researchers have reported that reduction in the cost and profitability are some of the major business motivators to become "green" in the supply chain $[26,27]$

2.2. Importance of Supplier Selection. Suppliers are the sellers that provide the raw material, services, or components which an organization may not be able to provide for it. In the present manufacturing environment for supply chain, the supplier is the major part of an organization. A suitable supplier is capable of offering the company the correct quality products and quantity at affordable prices at the best time [28]. The emergence of supply relationship has shown that suppliers are needed for a set of competences that form part of the supply system, which is capable of facing market competition [29].

\section{Material and Methods}

This study proposes an evaluation framework based on the DEMATEL methodologies to assist in GSCM strategic decisions. Firstly, we identify the green supplier evaluation criteria and present the proposed evaluation model in the following subsections, and then we mention the proposed techniques. According to previous researches, five main concepts for improving green supply chain management have been identified.

3.1. Green Supplier Evaluation Framework. The general view of the proposed green supplier evaluation framework is shown in Figure 1. Green supplier selection problem is a sort of complex multiple criteria decision making problem including both quantitative and qualitative factors, which may be inconsistent and may also be uncertain. Due to the nature of supplier selection, Multicriteria decision making 


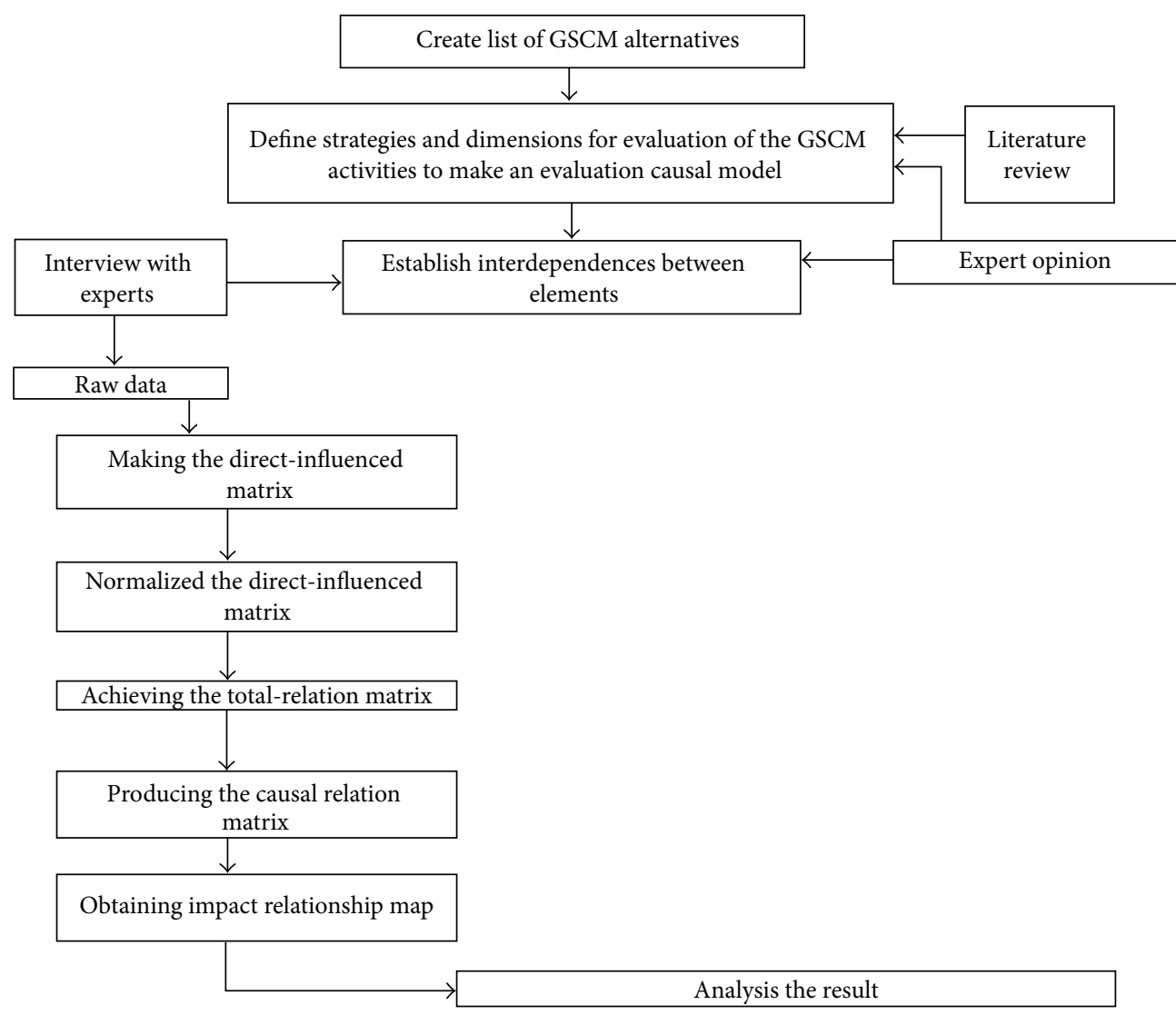

FIGURE 1: Green supplier evaluation framework.

(MCDM) methods are required to handle and solve the problem effectively. The techniques of MCDM are comprehensibly derived to manage this kind of problems [30].

\subsection{Criteria for Green Supplier Evaluation. According to} review of previous researches, five main concepts for improving green supply chain management have been identified: organizational performance (OP), green logistics (GL), green organizational activities (GOA), environmental protection (EP) and green supplier evaluation (GSE).

3.2.1. Organizational Performance. The requirements for strategic performance may not be environmentally based and are important to assist in identifying how well different alternative factors can be performed. They are essential because the selected alternative should not only support the green supply chain, it is also sensible of the area of business [31]. The adoption of OP measures was supported by many thinkers [32, 33]. One characteristic about the performance measure is that they are static. They are dynamic over time and are influenced by the product lifecycle.

3.2.2. Green Logistics. GL is the management activities to pursue customer satisfaction and social development goals, connecting the main body of green supply and demand, overcoming space and time obstacles to achieve efficient and rapid movement of goods and services. It inhibited the damage to environment to achieve the purification of the logistics environment and the best use of logistics resources. GL is a multilevel concept which includes both the green logistics business activities and social activities for green logistics management, standardization, and control [34].

3.2.3. Environmental Protection. Protection of the environment is a major area of green supply chain which compares the system of environmental protection like controlling all kinds of pollution and designs products according to green image, ISO 14001, and so forth. Major indicators are engaged in the recovery of resources conservation and resource utilization and resource type, environmental governance, environmental pollution, and reinvented ability. Moreover, it is made up of packaging materials, transport, emissions, garbage, and emissions $[35,36]$. In the US Air pollution Control Act and Water Pollution Control Act 1955 and 1948 were introduced by the Environmental Protection Agency (EPA).

3.2.4. Green Organizational Activities. GOA consists of different subjects such as recycling, reducing all kind of waste, reusing abilities, and so forth. In other words, managing of recovered products has become an important business for many firms. Used products from variable sources carried out the covering process to gain sustainable effect in the supply 
chain for lower cost [7]. According to Theyel [37], collection of schemes is classified according to material to sort and reuse products to reduce manufacturing costs. The products are obtained from the end users and returned to the factory for disposal.

3.2.5. Green Supplier Evaluation Criteria. It includes several concepts such as quality of services, new technologies, organization levels, and so forth that is, the level of relationship cooperation and attitudes are the major factors for GSC supplier suitability. The organizational cultural agreement and level of fitness are the sum of the attributes desires [38]. Moreover, one major part of GSE has been green consumption, its services and related products use which responds to the basic needs with better quality of life while natural resources and toxic material are maximized preventing future generation exposure to pollutants [39].

3.3. Green Supplier Evaluation Model. Based on criteria identification phase, direct and indirect effects and interactions between criteria are detected and evaluation model for green supplier selection is provided in Figure 2, a causal evaluation model (CEM).

For determining the relation and concepts, in this phase, five researchers from University Putra Malaysia (UPM), who work on SCM, are consulted. As a result the CEM has been proposed at the end of this phase.

In Figure 2 a straight line or an arc indicates the interactions between two criteria. For instance, when the factors of a cluster "green logistics" depend on factors of another "criteria", this relation is represented by an arrow from component "green logistics" to "Criteria."

From a mathematical view, the CEM says:

$$
\mathrm{CEM}=\mathrm{f}(\mathrm{GSE}, \mathrm{EP}, \mathrm{GOA}, \mathrm{GL}, \mathrm{OP})
$$

subject to

$$
\begin{aligned}
& \mathrm{GSE}=\mathrm{f}(\mathrm{EP}, \mathrm{GOA}, \mathrm{GL}, \mathrm{OP}), \\
& \mathrm{EP}=\mathrm{f}(\mathrm{GSE}, \mathrm{GOA}, \mathrm{GL}, \mathrm{OP}), \\
& \mathrm{GOA}=\mathrm{f}(\mathrm{GSE}, \mathrm{EP}, \mathrm{GL}, \mathrm{OP}), \\
& \mathrm{GL}=\mathrm{f}(\mathrm{GSE}, \mathrm{EP}, \mathrm{GOA}, \mathrm{OP}), \\
& \mathrm{OP}=\mathrm{f}(\mathrm{GSE}, \mathrm{EP}, \mathrm{GOA}, \mathrm{GL}) .
\end{aligned}
$$

\section{Application and Testing of the Model}

For testing the model, a case study with expert interview technique is applied for this research. The objects were 10 professional experts who are working in supply chain departments of Iran Khodro Co. (SAPCO). Each interview has been done individually by each expert and took time between minimum 45 minutes to maximum 60 minutes for each of them. During the interviews, questions did not follow. First, the evaluation model along with all components and interactions between criteria was described for each of them. Next step in interview is determining relations

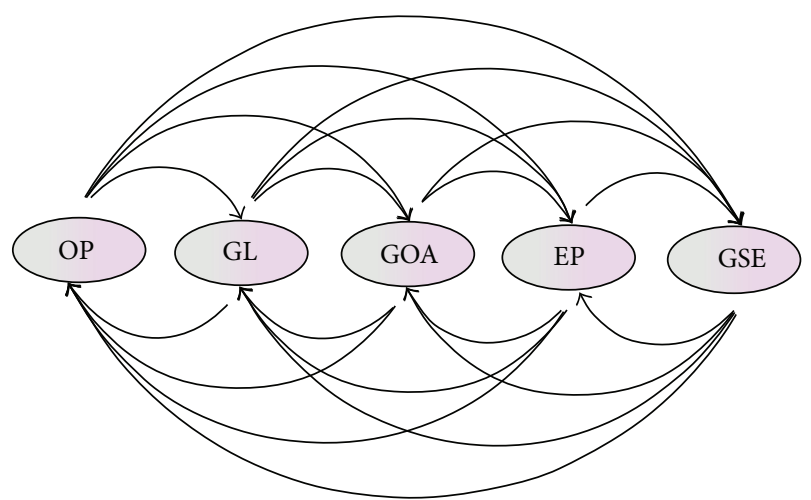

Figure 2: Causal evaluation model (CEM).

between concepts according to loops and arcs. In this step, consolation committee with experts determines the relations among influential factors in evaluation model. Each expert performs pairwise comparisons between each to factors and gives the score from 0 to 4 according to their experiences and believes that factor $i$ affects factor $j$. For this purpose, a group of engineers is selected form SAPCO (Supplying Automotive Parts Co.), the most important supplier and the main subset for Khorasan Iran Khodro Company. In fact, to apply DEMATEL technique, using expert's opinion among and within the elements to to paired comparison analysis is required.

\section{Case Analysis Method}

Green supplier selection problem is a sort of complex multiple criteria decision making problem including both quantitative and qualitative factors, which may be inconsistent and may be uncertain. Due to the nature of supplier selection, MCDM methods are required to handle and solve the problem effectively [40]. Multiple criteria decision making (MCDM) using the decision making trial and evaluation laboratory (DEMATEL) was proposed in this case analysis. The method of DEMATEL was chosen to assess the inner dependence level existence of green supply chain management, for selected practice indicators, and to build a network relationship map (NRM) as well as structural complex causal relationship visualization between the system criteria which acquires the criteria influence levels. In DEMATEL structure, each factor or part may exert on and obtain other higher or lower level factors. One of excellence of this technique rather than others decision making method in applying feedback application. The entire factors establish worth and importance of factors instead of considering only specific factors [41-43].

For applying DEMATEL, there are 6 main steps:

(1) making the direct-influenced matrix,

(2) calculating the direct-influenced matrix normalization,

(3) achieving the total-relation matrix,

(4) producing a causal diagram, 
(5) obtaining the inner dependence matrix and impact relationship map,

(6) obtaining the inner dependence matrix. In this step, the sum of each column in total-relation $n \times n$ matrix is equal to 1 by the normalization method, and then the inner dependence matrix can be acquired.

5.1. The Procedures of the DEMATEL Technique. The procedures of the DEMATEL method can be expressed as follow.

Step 1 (finding the direct-relation (average) matrix). Four scales determine the values of relationships among different factors according to the experts' opinion:

$0=$ no influence, $1=$ low influence, $2=$ high influence, $3=$ very high influence.

In DEMATEL technique, $H$ experts and $n$ factor (criteria) have to be considered. Each expert answers the certain questions to demonstrate the degree of a criterion $i$ effect criterion $j$ based on her or his beliefs. For now, $a_{i j}$ donates pair wise comparisons between any two criteria and it is assigned integer score ranging from $0,1,2,3,4$. The scores are given by each expert and $X^{1} X^{2} \cdots X^{H}$ are answers to each of them that make the $n \times n$ nonnegative matrix $X^{k}=\left[x_{i j}^{k}\right]_{n \times n}$, with $1<k<H$. A high score indicates a belief that greater improvement in $i$ is required to improve $j$. Then it is possible to calculate the $n \times n$ average matrix $A$ on account of all expert's opinions by averaging the $H$ their scores as follows:

$$
\left[a_{i j}\right]_{n \times n}=\frac{1}{H} \sum_{k=1}^{H}\left[x_{i j}^{k}\right]_{n \times n} .
$$

The initial direct effects that each criterion exerts on and receives from other criteria are exposed in the average matrix $\left[a_{i j}\right]_{n \times n}$, which is also called the initial direct influenced. Moreover, in this level, gaining the causal effect between each pair of criteria in a system by drawing an influence map will be possible, also as follows:

(1) If $a_{i j} \leq 1$ (independent is identified among all criteria; otherwise, nonindependent will be identified).

(2) The structural relations between the criteria of a system are converted to intelligible and logical map of the system. Figure 1 shows an example of such a network influence map which helps to explain the structure of the factors. $C_{i}$ represents a criterion in the system. As an instance the arrow from $C_{1}$ to $C_{2}$ indicates the effect that $C_{1}$ has on $C_{2}$ and the power of its effect is 3 .

Step 2 (normalize the initial direct-relation matrix). Normalized initial direct relation matrix $D$ is obtained by normalizing the average matrix $A$, in the following formulas:

$$
\begin{gathered}
S=\max \left\{\max \sum_{j=1}^{n} a_{i j}, \max \sum_{i=1}^{n} a_{i j}\right\}, \\
D=\frac{A}{S} .
\end{gathered}
$$

TABLE 1

\begin{tabular}{|c|c|c|c|c|c|}
\hline \multicolumn{6}{|c|}{ Main criteria } \\
\hline & OP & GL & GOA & $\mathrm{EP}$ & GSE \\
\hline $\begin{array}{l}\text { Organizational performance } \\
\text { (OP) }\end{array}$ & 0.000 & 0.257 & 0.000 & 0.000 & 0.000 \\
\hline Green logistics (GL) & 0.272 & 0.000 & 0.000 & 0.250 & 0.000 \\
\hline $\begin{array}{l}\text { Green organizational activities } \\
\text { (GOA) }\end{array}$ & 0.000 & 0.228 & 0.000 & 0.235 & 0.000 \\
\hline Environmental protection (EP) & 0.000 & 0.221 & 0.206 & 0.000 & 0.000 \\
\hline Green supplier evaluation (GSE) & 0.279 & 0.250 & 0.228 & 0.243 & 0.000 \\
\hline
\end{tabular}

\begin{tabular}{lccccc}
\hline & OP & GL & GOA & EP & GSE \\
\hline Organizational performance & 0 & 3.5 & 0 & 0 & 0 \\
Green logistics & 3.7 & 0 & 0 & 3.4 & 0 \\
Green organizational activities & 0 & 3.1 & 0 & 3.2 & 0 \\
Environmental protection & 0 & 3 & 2.8 & 0 & 0 \\
Green supplier evaluation & 3.8 & 3.4 & 3.1 & 3.3 & 0 \\
\hline
\end{tabular}

TABLE 2: Direct-relation matrix $D$.

As a result total direct influences that criterion $i$ gives to the other criteria are gained by sum of each row $i$ of matrix $A$ as well as the sum of each column $j$ represent most direct effects on others by total direct effects of the criterion. Likewise, since the sum of each column $j$ of matrix $A$ represents the total direct effects received to other criteria by criterion $i, \max \sum_{i=1}^{n} a_{i j}$ represents the total direct effects that the criterion $j$ receives the most direct effects from other criteria and the positive numerical $s$ takes the smaller of the two as the upper bound, and the matrix $D$ is obtained by dividing each element of $A$ by the scalar $s$. Each element $d_{i j}$ of matrix $D$ is between zero and less than 1: $0<d_{i j}<1$.

Step 3 (calculate the total-relation matrix). A continuous reducing of the indirect effects of problems beside the powers of matrix $D$, like to an engrossing Markov chain matrix, guarantees convergent solutions to the matrix inversion.

Note that

$$
\begin{aligned}
& D^{2}, D^{3}, \ldots, D^{\infty}, \\
& \lim _{m \rightarrow \infty} D^{m}=[0]_{n \times n},
\end{aligned}
$$

$[0]_{n \times n}$ is a $(n \times n)$ null matrix.

The total relation matrix $T_{n \times n}$ is achieved as follow:

$$
\begin{aligned}
\sum_{m=1}^{\infty} D_{i} & =D+D^{2}+D^{3} \cdots D^{m} \\
& =D\left(I+D+D^{2}+\cdots+D^{m-1}\right) \\
& =D(I-D)^{-1}(I-D)\left(I+D+D^{2}+\cdots+D^{m-1}\right) \\
& =D(1-D)^{-1}\left(I-D^{m}\right)=D(I-D)^{-1} .
\end{aligned}
$$

I: identity matrix, $T$ : total-relation matrix $\left([T]_{n \times n}\right)$. 
TABLE 3: Total-relation matrix.

\begin{tabular}{lcccccccc}
\hline & \multicolumn{3}{c}{ Main criteria } & & & & \\
& OP & GL & GOA & EP & GSE & $R+C$ & $R-C$ \\
\hline Organizational performance (OP) & 0.081 & 0.299 & 0.016 & 0.079 & 0.000 & 0.475 & 1.477 & -0.527 \\
Green logistics (GL) & 0.316 & 0.163 & 0.063 & 0.306 & 0.000 & 0.848 & 2.511 & -0.815 \\
Green organizational activity (GOA) & 0.093 & 0.342 & 0.069 & 0.337 & 0.000 & 0.841 & 1.544 & 0.138 \\
Environmental protection (EP) & 0.089 & 0.327 & 0.234 & 0.137 & 0.000 & 0.787 & 2.098 & -0.524 \\
Green supplier evaluation (GSE) & 0.423 & 0.532 & 0.321 & 0.452 & 0.000 & 1.728 & 1.728 & 1.728 \\
C & 1.002 & 1.663 & 0.703 & 1.311 & 0.000 & & \\
\hline
\end{tabular}

The sum of rows and sum of columns of the total relation matrix $T$ are computed as an $r$ and $c_{n \times 1}$ vectors, one has

$$
\begin{aligned}
& {\left[r_{i}\right]_{n \times 1}=\left(\sum_{j=1}^{n} t_{i j}\right)_{n \times 1},} \\
& {\left[c_{j}\right]_{1 \times n}=\left(\sum_{i=1}^{n} t_{i j}\right)_{1 \times n} .}
\end{aligned}
$$

$\left[r_{i}\right]_{n \times 1}$ demonstrates the total effects, both direct and indirect, given by criterion $i$ to the other criteria $j=1,2, \ldots, n$; similarly $\left[c_{j}\right]_{1 \times n}$ represents total effects, direct and indirect, received by criterion $j$ from the other criteria $i=1,2, \ldots, n$. As a result, while $i=j$ the $\operatorname{sum}\left(r_{i}+c_{i}\right)$ that is called "prominence" proves the degree of importance role of criterion $i$ in system and also gives an index that shows the total effects both given and received by criterion $i$. likewise, the $\left(r_{i}-c_{i}\right)$ that in called "Relation" shows the net effect that criterion $i$ donates to the system. When $\left(r_{i}-c_{i}\right)$ is positive, criterion $i$ will be to the cause group, and when $\left(r_{i}-c_{i}\right)$ is negative, criterion $i$ is a net receiver.

\section{Case Analysis, Result, and Discussion}

In this phase, both direct and indirect influences will be achieved by applying DEMATEL technique and finally criterions will be divided to cause and effect groups.

Step 1. At first, a committee was formed including the ten experts from Supply Chain Department in an automotive company named Iran Khordo, the biggest automotive company in the middle east.

Step 2. Finding the initial direct-relation (Average) matrix: Table 2 illustrates the values of relationships between criteria that are determined by pair wise comparisons between any two criteria according to the experts' opinion and they are assigned integer score ranging from 0 to 4 . The values in Table 1 are calculated according to (3).

In addition, Figure 3 demonstrates the relations among the influential main criteria. The numbers show the direct effect that each cluster gives to other clusters or receives from them.

Step 3. Normalized initial direct relation matrix $D$ is obtained by normalizing the initial matrix $A$ according to (4); matrix $D$ is indicated in Table 2.
TABLE 4: Cause and effect group of environmental protection.

\begin{tabular}{cc}
\hline Cause group & $\begin{array}{c}\text { Green supplier evaluation } \\
\text { Green organizational activities }\end{array}$ \\
\hline Effect group & Green logistics \\
& $\begin{array}{c}\text { Organizational performance } \\
\text { Environmental protection }\end{array}$ \\
\hline
\end{tabular}

TABLE 5: The inner dependence of environmental protection.

\begin{tabular}{lccccc}
\hline & OP & GL & GOA & EP & GSE \\
\hline $\begin{array}{l}\text { Organizational performance } \\
\text { (OP) }\end{array}$ & 0.171 & 0.629 & 0.034 & 0.166 & 0.000 \\
$\begin{array}{l}\text { Green logistics (GL) } \\
\text { Green organizational activity }\end{array}$ & 0.373 & 0.192 & 0.074 & 0.361 & 0.000 \\
(GOA) & 0.111 & 0.407 & 0.082 & 0.401 & 0.000 \\
Environmental protection (EP) & 0.113 & 0.416 & 0.297 & 0.174 & 0.000 \\
Green supplier evaluation (GSE) & 0.245 & 0.308 & 0.186 & 0.262 & 0.000 \\
\hline
\end{tabular}

Step 4. Calculating the total-relationships matrix $T$ for causal relation by achieving the $D(I-D)^{-1}$ according (6). Table 3, indicates the total-relation matrix $T$.

By considering proposed evaluation framework, green supplier evaluation (GSE) has significant effect on other four clusters and receives effects from none of them. In other words, all criteria have been affected by GSE. Besides, green organizational activities (GOA) receive and give influences equally in spite of other three main criteria. It is clear that GSE belongs to the cause group and also GOA can be part of the cause group. Eventually, results show GSE by the greatest $(R-C)$ score with 1.728 is part of the cause group and GOA are located in the second place of cause group with 0.138 . In addition green logistics (GL) has the maximum $(R+C)$ score that is showing it is the most important criteria for the GSC improvement, but the $(D-R)$ value of GL $(-0.815)$ is the smallest score among effect factor. Indeed, the degree of influential impact $D$ and degree of influenced impact $C$ which are 0.848 and 1.663, respectively, are the highest scores of all factors. It means that GL is an effect factor; it noticeably affects other aspects and on the entire system.

Unconformably with Table 4, all five criteria are divided into the cause and effect groups. And with Figure 4, Impact Relation Map for main criteria is shown. 
TABLE 6: Ranking dimensions evaluation model.

\begin{tabular}{lccc}
\hline & Ranking of important factors & Ranking of affected factors & Ranking of influential factors \\
\hline 1 & Green logistics & Green logistics & Green supplier evaluation \\
2 & Environmental protection & Environmental protection & Green logistics \\
3 & Green supplier evaluation & Organizational performance & Environmental protection \\
4 & Green organizational activity & Green organizational activity & Green organizational activity \\
5 & Organizational performance & Green supplier evaluation & Organizational performance \\
\hline
\end{tabular}

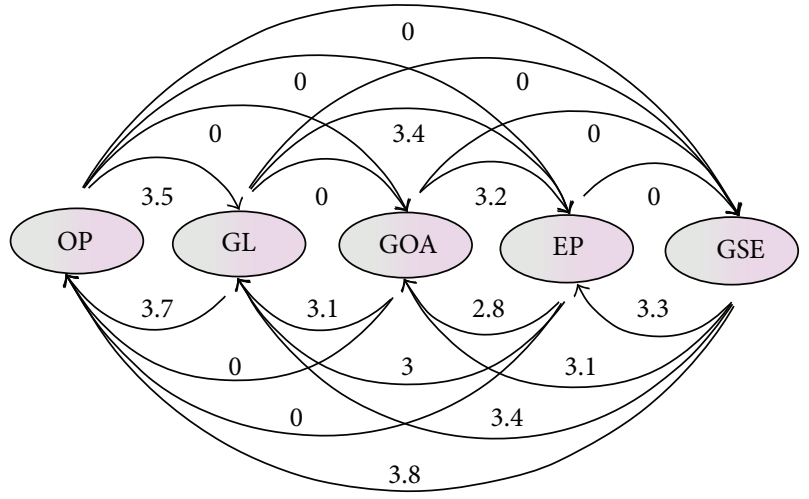

Figure 3: Graphical causal relation criteria.

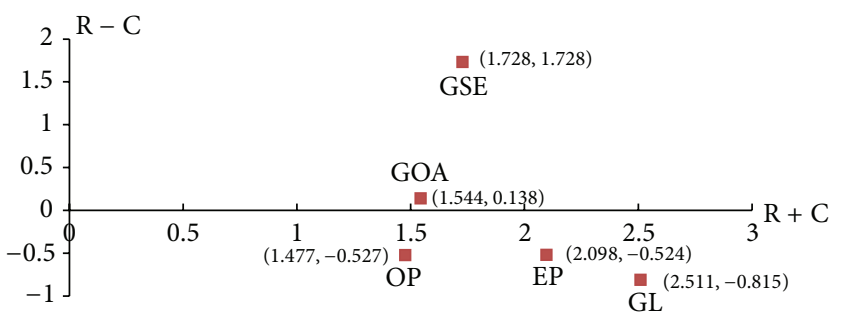

FIGURE 4: Impact Relation Map for main criteria.

By considering Table 4, GSE and GOA belong to the case group. It means that both of these criteria have significant impacts on other criteria in the causal model. In other words by improving GSE and GOA, a noticeable development will be happened on other criteria and in a whole system.

According to Figure 4, GSE is the most influential factor and GL is the most important factor in the whole system.

As in Table 5, by the normalization method, the sum of each column in total-relation matrix is equal to 1 and then the inner dependence matrix can be acquired. By considering Table 5, the comparison between criteria becomes easier because of the same scale.

By considering the result, all five factors of evaluation model can be prioritized based on the most important, most influential, and the most affected. Table 6 demonstrates ranking of criteria on framework.

\section{Conclusion}

This study proposes the evaluation framework to improve green supply chain by applying the DEMATEL method to analyze and prioritize essential factors in green supplier selection on automotive industries. As a conclusion, green Logistics, organizational performance, green organizational activities, environmental performance and green supplier evaluation are ranked according to power of influence and degree of importance in a whole green supply chain system; therefore, manufacturers and suppliers will be able to develop their activities according to the green image by adopting the results of this study. In addition, there is not any research in this area that presents the same result, so there is no way to compare outcomes.

On one hand, the results of this research enable enterprises to find out which suppliers are suitable by considering environmental and traditional practices in proposed model. The proposed model can be applied in two purposes: first, it would help enterprises to find out which factors are more effective and important to select the best possible green supplier with regard to both direct and indirect relations between elements. On the other hand, if a company is a supplier for other companies and wants to implement environmental practices in own manufacturing system, it can provide the model the whole system.

In fact, the case study of this research finds criteria that influence green supplier selection and set up the strategy map among these criteria by using DEMATEL technique. The direct relationship map indicates interdependencies among all criteria and their strengths in model. The current study finds that both green supplier evaluation and green organizational activities have a considerable impact on the other criteria; so by improving these 2 criterions, other criteria will be improved automatically.

For further studies we suggest more case studies to valid CEM in different industries and also to gain more understanding of interrelationship effects of GSE, EP, GOA, GL, and OP. The CEM can be modified by using hybrid fuzzy DEMATEL.

\section{Conflict of Interests}

The authors declare no possible conflict of interests.

\section{References}

[1] A. Sanayei, S. F. Mousavi, and A. Yazdankhah, "Group decision making process for supplier selection with VIKOR under fuzzy environment," Expert Systems with Applications, vol. 37, no. 1, pp. 24-30, 2010.

[2] P. Ramin, "Modeling for green management," in Proceedings of the Conference on Management, pp. 23-26, Kerman, Iran, October 2009. 
[3] J. Sarkis, "A strategic decision framework for green supply chain management," Journal of Cleaner Production, vol. 11, no. 4, pp. 397-409, 2003.

[4] A. H. I. Lee, H. Y. Kang, C. F. Hsu, and H. C. Hung, "A green supplier selection model for high-tech industry," Expert Systems with Applications, vol. 36, no. 4, pp. 7917-7927, 2009.

[5] W.-N. Pi and C. Low, "Supplier evaluation and selection via Taguchi loss functions and an AHP," International Journal of Advanced Manufacturing Technology, vol. 27, no. 5-6, pp. 625630, 2006.

[6] A. Karunaratne, L. M. Chi, H. S. Min, and S. Sorooshian, "Supply chain strategy," International Journal of Innovative Ideas, vol. 12, no. 4, pp. 7-8, 2012.

[7] W. F. Oh, I. Resty, X. Y. Yang, and S. Sorooshian, "Strategy for supply chains," Journal of Science, vol. 2, no. 1, p. 90, 2012.

[8] R. Handfield, R. Sroufe, and S. Walton, "Integrating environmental management and supply chain strategies," Business Strategy and the Environment, vol. 14, no. 1, pp. 1-19, 2005.

[9] J. D. Linton, R. Klassen, and V. Jayaraman, "Sustainable supply chains: an introduction," Journal of Operations Management, vol. 25, no. 6, pp. 1075-1082, 2007.

[10] A. Amid, S. H. Ghodsypour, and C. O’Brien, "Fuzzy multiobjective linear model for supplier selection in a supply chain," International Journal of Production Economics, vol. 104, no. 2, pp. 394-407, 2006.

[11] H. J. Wu and S. Dunn, "Environmentally responsible logistics systems," International Journal of Physical Distribution \& Logistics Management, vol. 25, pp. 20-38, 1995.

[12] S. J. Lin, I. J. Lu, and C. Lewis, "Grey relation performance correlations among economics, energy use and carbon dioxide emission in Taiwan," Energy Policy, vol. 35, no. 3, pp. 1948-1955, 2007.

[13] Y.-J. Chen, "Structured methodology for supplier selection and evaluation in a supply chain," Journal of Information Sciences, vol. 19, pp. 1651-1670, 2011.

[14] J. D. Linton, R. Klassen, and V. Jayaraman, "Sustainable supply chains: an introduction," Journal of Operations Management, vol. 25, no. 6, pp. 1075-1082, 2007.

[15] J. Sarkis, "A strategic decision framework for green supply chain management," Journal of Cleaner Production, vol. 11, no. 4, pp. 397-409, 2003.

[16] W.-N. Pi and C. Low, "Supplier evaluation and selection via Taguchi loss functions and an AHP," International Journal of Advanced Manufacturing Technology, vol. 27, no. 5-6, pp. 625630, 2006.

[17] U. P. Wen and J. M. Chi, "Developing green supplier selection procedure: a DEA approach," in Proceedings of the 17th International Conference on Industrial Engineering and Engineering Management (IE \& EM '10), pp. 70-74, Xiamen, China, October 2010.

[18] K. L. Choy, W. B. Lee, H. C. W. Lau, S. C. K. So, and V. Lo, "An enterprise collaborative management system: a case study of supplier selection in new product development," International Journal of Technology Management, vol. 28, no. 2, pp. 206-226, 2004.

[19] S. Chopra and P. Meindl, Supply Chain Management: Strategy, Planning, and Operations, Prentice-Hall, Upper Saddle River, NJ, USA, 2001.

[20] Q. Su, J. H. Shi, and S. J. Lai, "Study on supply chain management of Chinese firms from the institutional view," International Journal of Production Economics, vol. 115, no. 2, pp. 362-373, 2008.
[21] J. D. Linton, R. Klassen, and V. Jayaraman, "Sustainable supply chains: an introduction," Journal of Operations Management, vol. 25, no. 6, pp. 1075-1082, 2007.

[22] R. Ganeshan and T. P. Harrison, An Introduction to Supply Chain Management, Department of Management Sciences and Information Systems, Pennsylvania State University, PA, USA, 1995.

[23] J. T. Mentzer, W. DeWitt, J. S. Keebler et al., "Defining supply chain management," Journal of Business Logistics, vol. 22, no. 2, p. 18, 2001.

[24] P. Rao and D. Holt, "Do green supply chains lead to competitiveness and economic performance?" International Journal of Operations and Production Management, vol. 25, no. 9, pp. 898916, 2005.

[25] H. J. Wu and S. Dunn, "Environmentally responsible logistics systems," International Journal of Physical Distribution \& Logistics Management, vol. 25, pp. 20-238, 1995.

[26] N. Darnall, G. J. Jolley, and R. Handfield, "Environmental management systems and green supply chain management: complements for sustainability?" Business Strategy and the Environment, vol. 17, no. 1, pp. 30-45, 2008.

[27] S. K. Srivastava and R. K. Srivastava, "Managing product returns for reverse logistics," International Journal of Physical Distribution and Logistics Management, vol. 36, no. 7, pp. 524546, 2006.

[28] L. De Boer, E. Labro, and P. Morlacchi, "A review of methods supporting supplier selection," European Journal of Purchasing and Supply Management, vol. 7, no. 2, pp. 75-89, 2001.

[29] E. Esposito and R. Passaro, "The evolution of supply chain relationships: an interpretative framework based on the Italian inter-industry experience," Journal of Purchasing and Supply Management, vol. 15, no. 2, pp. 114-126, 2009.

[30] N. Aissaoui, M. Haouari, and E. Hassini, "Supplier selection and order lot sizing modeling: a review," Computers and Operations Research, vol. 34, no. 12, pp. 3516-3540, 2007.

[31] Y. Yang and L. Wu, "Grey entropy method for green supplier selection," in Proceedings of the International Conference on Wireless Communications, Networking and Mobile Computing (WiCOM '07), pp. 4677-4680, Shanghai, China, September 2007.

[32] R. Handfield, R. Sroufe, and S. Walton, "Integrating environmental management and supply chain strategies," Business Strategy and the Environment, vol. 14, no. 1, pp. 1-19, 2005.

[33] D. J. Ketchen and G. T. M. Hult, "Bridging organization theory and supply chain management: the case of best value supply chains," Journal of Operations Management, vol. 25, no. 2, pp. 573-580, 2007.

[34] L. Zheng and J. Zhang, "Research on green logistics system based on circular economy," Asian Social Science, vol. 6, pp. 116119, 2010.

[35] P. K. Humphreys, Y. K. Wong, and F. T. S. Chan, "Integrating environmental criteria into the supplier selection process," Journal of Materials Processing Technology, vol. 138, no. 1-3, pp. 349-356, 2003.

[36] X. Ma and T. Liu, "Supplier selection analysis under the green supply chain," in Proceedings of the International conference on Automotive and Logistics, vol. 5, pp. 205-209, 2011.

[37] G. Theyel, "Customer and supplier relations for environmental performance," Greener Management International, no. 35, pp. 61-69, 2001.

[38] S. K. Srivastava, "Green supply-chain management: a state-ofthe-art literature review," International Journal of Management Reviews, vol. 9, no. 1, pp. 53-80, 2007. 
[39] E. Fontela and A. Gabus, "The DEMATEL observer," DEMATEL Report, Battelle Geneva Research Center, Geneva, Switzerland, 1976.

[40] J. L. Yang and G.-H. Tzeng, "An integrated MCDM technique combined with DEMATEL for a novel cluster-weighted with ANP method," Expert Systems with Applications, vol. 38, no. 3, pp. 1417-1424, 2011.

[41] M. Amiri, J. S. Sadaghiyani, N. Payani, and M. Shafieezadeh, "Developing a DEMATEL method to prioritize distribution centers in supply chain," Journal of Management Science Letters, vol. 1, no. 3, p. 307, 2011.

[42] S. Sorooshian, A. Anvari, M. Salimi, and E. Falatoonitoosi, "Interrelation study of entrepreneur's capability," Wold Applies Sciences Journal, vol. 17, no. 7, pp. 818-820, 2012.

[43] E. Falatoonoitoosi, Z. Leman, S. Sorooshian, and M. Salimi, "Decision making trial and evaluation laboratory," Research Journal of Applied Sciences, Engineering, and Technology, vol. 5, no. 13, pp. 3475-3480, 2013. 


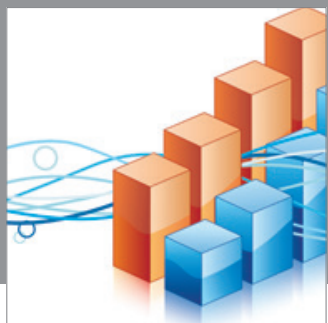

Advances in

Operations Research

mansans

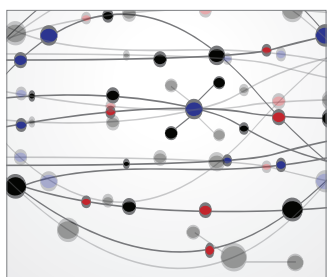

The Scientific World Journal
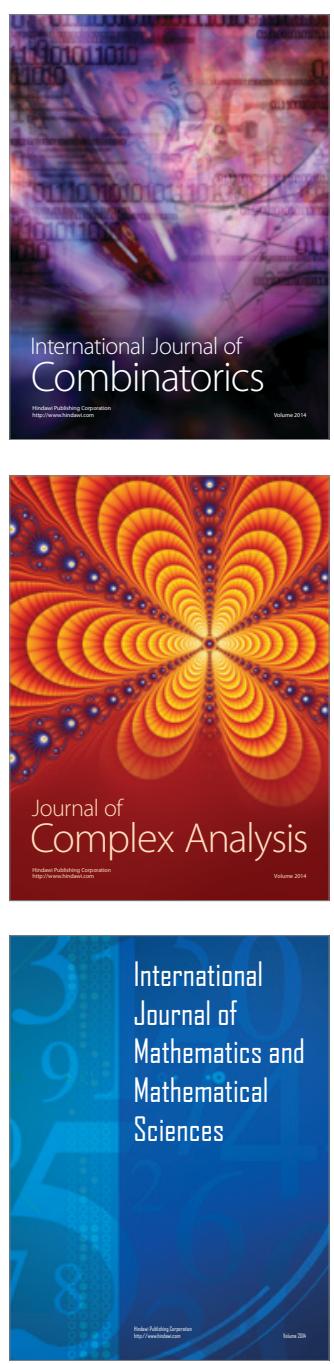
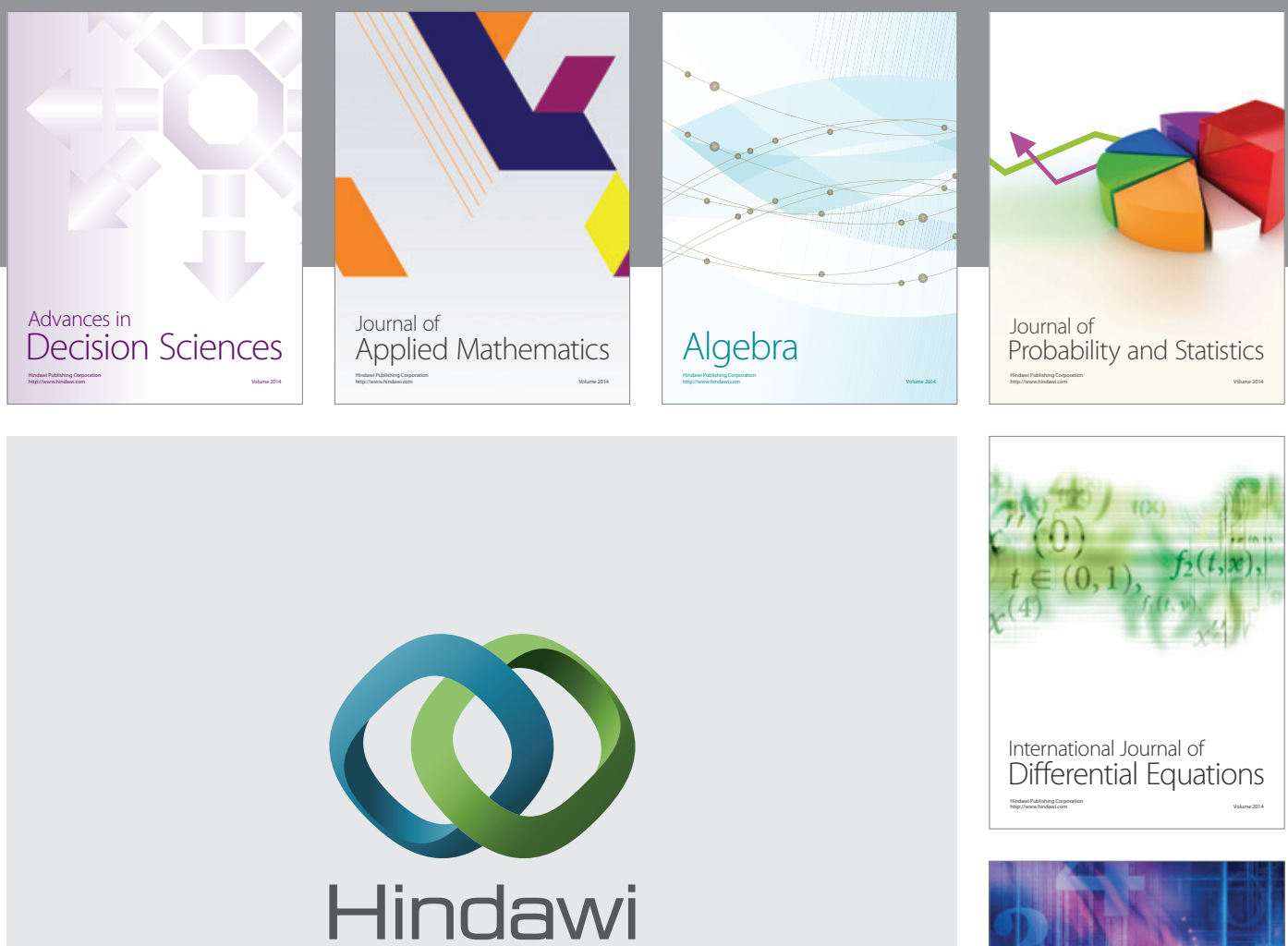

Submit your manuscripts at http://www.hindawi.com
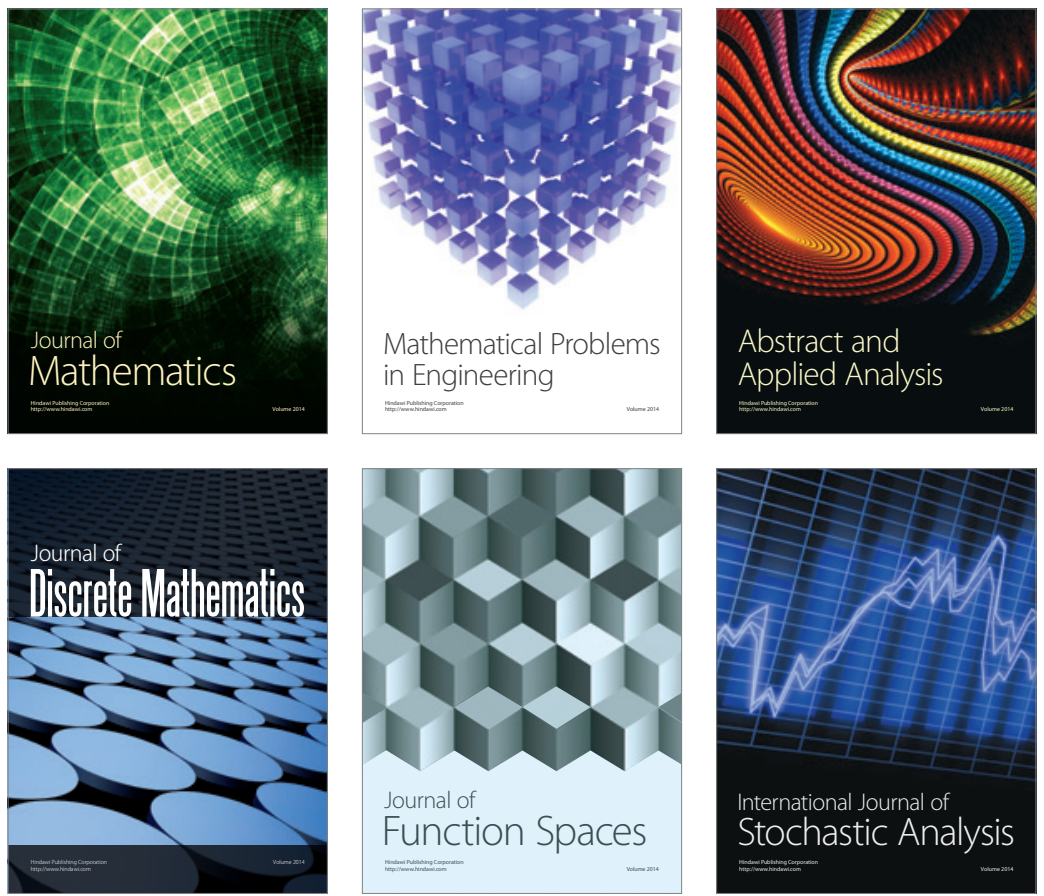

Journal of

Function Spaces

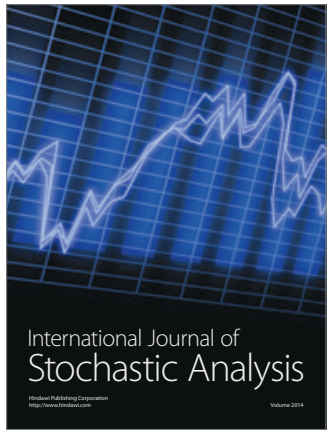

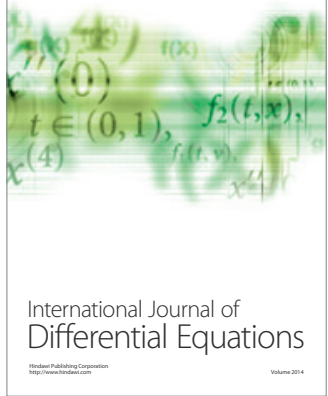
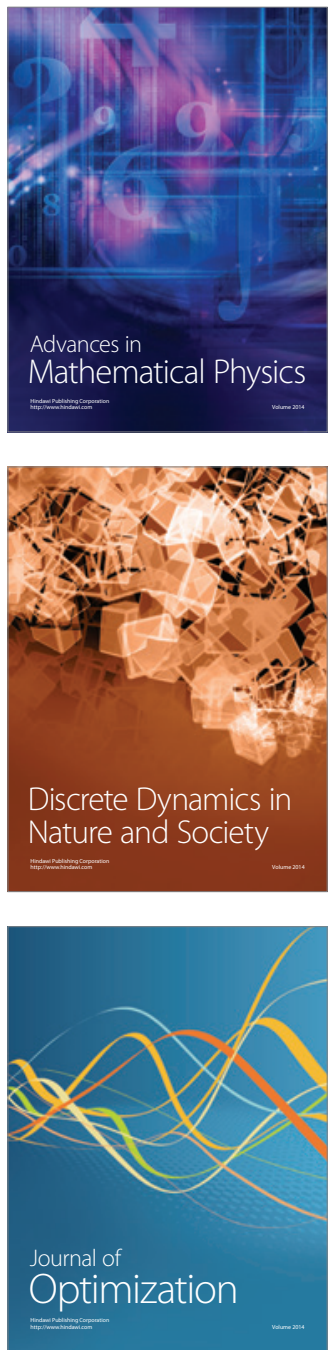